\title{
Adult Cardiac surgery in the elderly (octogenarians and above) - are we getting better?
}

\author{
Faisal Mourad 1, Vivek Srivastava2, M. Khan2, and Andrew Duncan2 \\ 1Dept. of Cardiothoracic Surgery, Ain Shams University, Cairo \\ 2Dept. of Cardiothoracic Surgery, Victoria hospital, Blackpool \\ Correspondence: faisalmourad@ hotmail.com
}

\begin{abstract}
Background: Cardiac surgery is being performed more frequently on the elderly. With an over-stretched budget to care for an aging population, our objective was to determine if we are getting better at managing these frail patients.

Methods: Institutional database was used to identify patients aged 80 or above undergoing cardiac surgery in Blackpool Victoria hospital NHS foundation trust, UK between June1996 and June.2013. Outcomes between group 1(June1996-Dec.2008; n=472) were compared to Group 2(Jan.2009-June.2013; n=607). Long-term survival was ascertained using NHS tracing-service.
\end{abstract}

Results: Group 2 patients included more males and had higher mean age and higher additive and logistic EurOSCORE I. Operative mortality was significantly improved while other complication rates were similar. Overall mean long-term survival was $114.1 \pm 4.1$ months.

Conclusions: In the past 4 years despite the tight NHS budgets we have been able to double our workload of elderly patients' population and improve their hospital mortality with expectation of good long-term survival.

Keywords: octogenarians, adult cardiac surgery

\section{Background}

In our modern times there's an ever going increase in the average life expectancy. With this increase of age there is a higher incidence of cardiovascular disease and more elderly patients require cardiac surgery nowadays (1). Medical advances in the pre- and postoperative care have led to the possibility that an increasing number of elderly patients can be operated on safely and have a satisfactory outcome. Currently, coronary artery bypass surgery, aortic and mitral valve surgery and major surgery of the aorta are performed in elderly patients with a satisfactory outcome (2,3). Nevertheless, this cohort of patients has an inherent potential of developing higher morbidity rates and the risk for these patients is only acceptable in the absence of comorbidities (4). It is only with proper patient selection criteria, attention to details and a high quality surgery that we would expect to see a satisfactory outcome. The care of elderly cardiac surgery patients is a multidisciplinary team approach requiring the cooperation of geriatricians, anesthesiologists, cardiologists, and cardiac surgeons, in order to obtain a specific treatment for each individual patient.

Methods

This study is representative of our practice in
Blackpool Victoria hospital NHS foundation trust, UK. Our institutional database was used to identify patients aged 80 or above undergoing cardiac surgery between June 1996 and June 2013. Our aim was to asses our unit's results in terms of morbidity and mortality over the last 4 years in this frail group of patients and compare the results to our early practice. We divided our patients into two groups, group 1 (June1996Dec.2008; $\mathrm{n}=472$ ) compared to Group 2(Jan.2009June.2013; n=607). Long-term survival was ascertained using NHS tracing-service.

\section{Results}

\section{Descriptive and Preoperative results:}

Results showed that the current study population had a mean age of those in group 1 being $82.23 \pm 2.33$ vs $82.89 \pm 2.66$ in group $2 \mathrm{p}=<0.01$ (Table 1 ). The age distribution is shown in (figure 1). The female population were less frequent in group 2 than group 1 $38.7 \% \quad(n=235) \quad$ compared to $47.2 \% \quad(n=223)$ respectively. Both groups had similar preoperative morbidity with regards to diabetes, renal dysfunction and LV functions (Table 1). Hypertension and pulmonary problems were significantly lower in group 
1 compared to group $2272(57.6 \%)$ and $428(70.5 \%)$ $\mathrm{p}<0.01 ; 38(8 \%)$ and $94(15.5 \%) \mathrm{p}<0.01$ (Table 1$)$.

There was no statistical difference in terms of the different types of operations performed the variety and distribution of those operations is shown in (Fig. 2), or the priority of surgery in the two groups (Table 2). Both the additive and logistic Euroscore 1 were significantly higher in group 2 than group 1 (Table 2). Euroscore 2 could not be calculated as this is a retrospective study and the data was not available back in the time that would allow us to calculate it.

Figure (1): Age distribution

\section{Outcomes:}

Despite the lack of statistical difference yet, all parameters in the postoperative recovery period showed an improvement in the last 4-year period over the earlier years of cardiac surgery practice (Table 3) including postoperative stroke rate, reoperation for bleeding, and the need for hemofiltration, ICU stay and overall reduction in hospital stay.

The average hospital stay was between 13.7 and 14.42 days which is more than our 60 years old patients who had a mean hospital stay of 8.35 days between 2009 and 2013. The hospital mortality showed a significant improvement being $4.78 \% \mathrm{n}=29$ in group 2 in comparison to group $110.8 \% \mathrm{n}=51$.

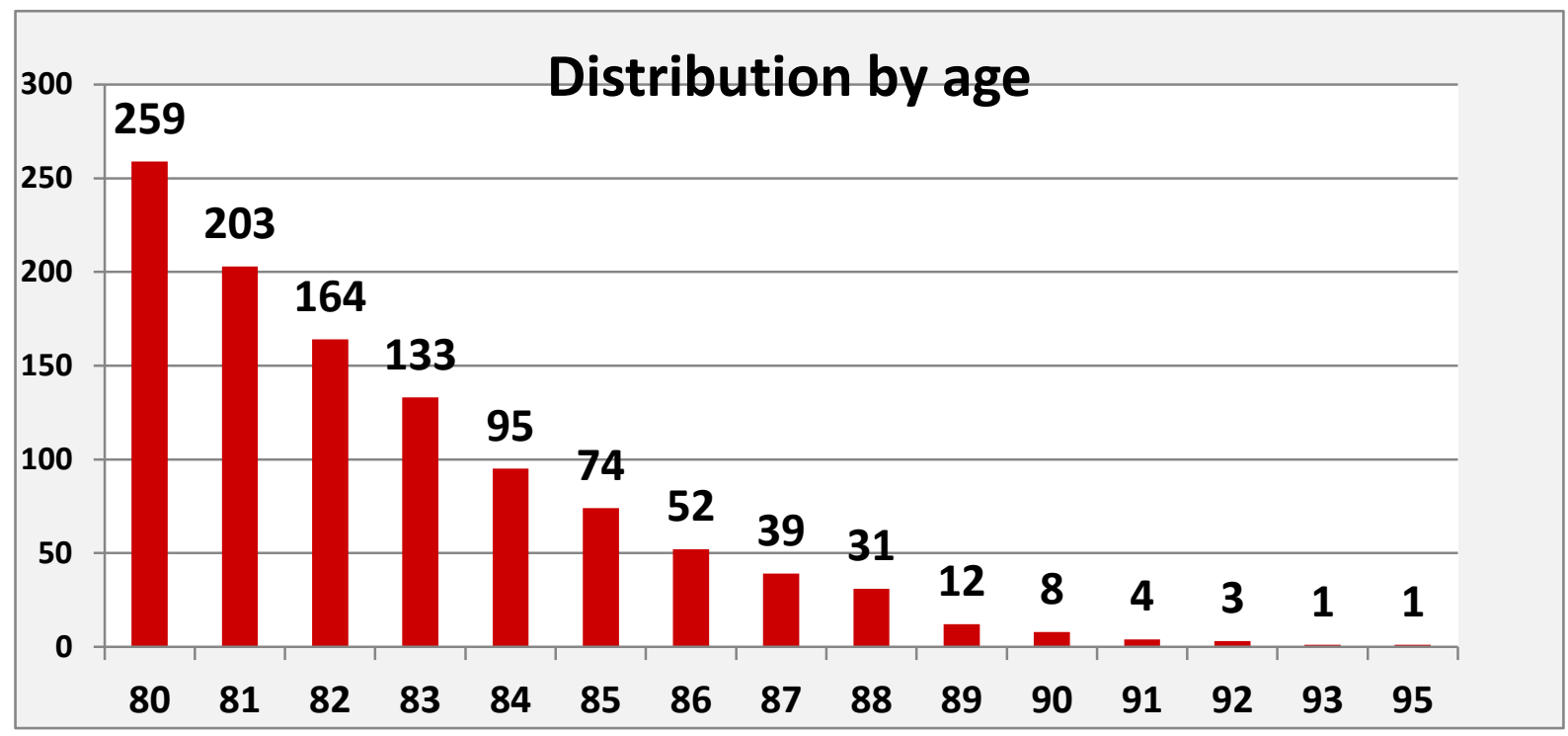

Figure (2): Types and distribution of the different types of cardiac procedures

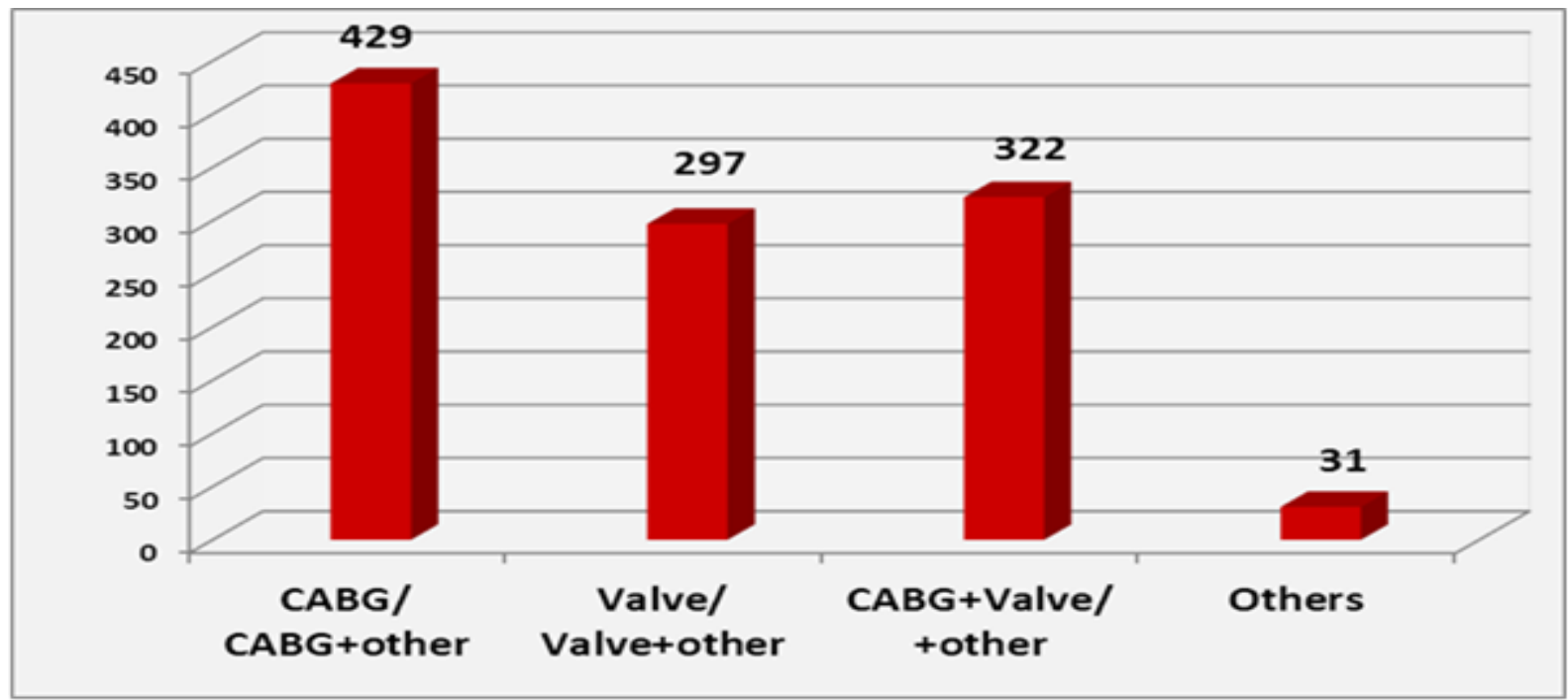




\section{Discharge destination}

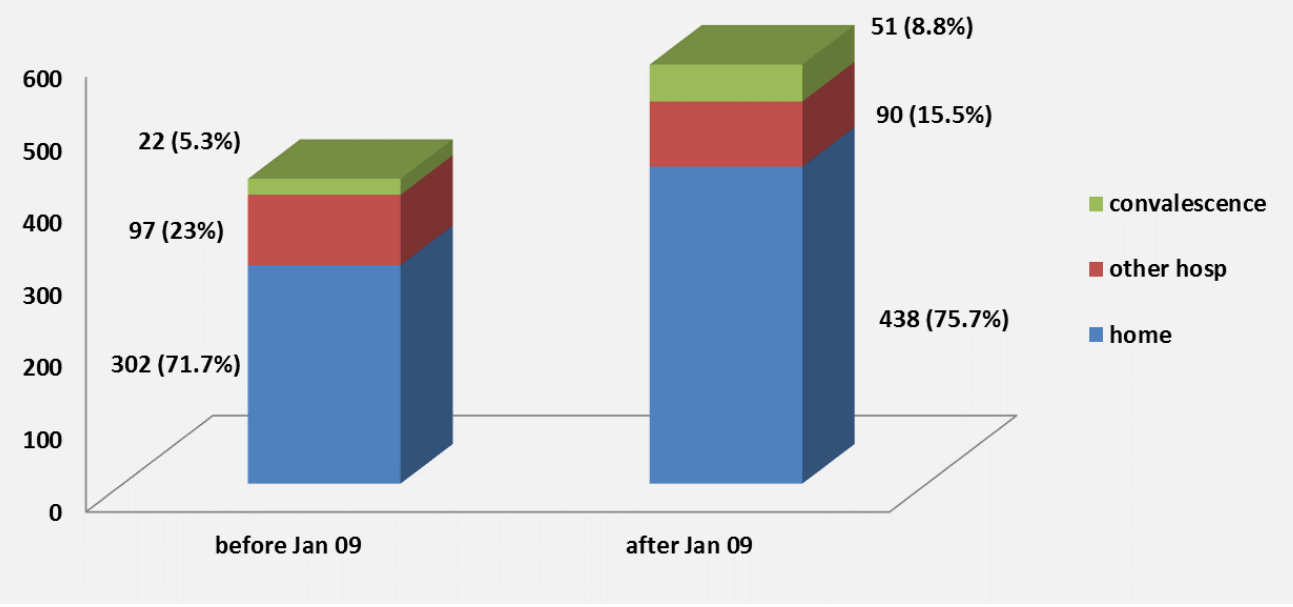

Figure (3):

Discharge

destination
Our long term follow up using the NHS tracing system was able to pick up patients up to ten years postoperatively. The number of hospital survivors was 999 and those of late deaths (after 30 days from date of discharge) was $238.71 .7 \%$ of group 1 and $75.7 \%$ of group 2 were discharged home Fig. (3). The mean survival time was $114 \pm 4.05$ months and the median was $110 \pm 6.4$ months Fig. (4). The survival curve before and after 2009 reflects a probable better long term survival after 2009 Fig. (5).

\section{Discussion:}

The major concerns with elderly cardiac surgery are raising costs of care, high operative mortality and the uncertainty about quality of life after surgery. Many studies revealed a more conservative trend towards the management of those patients (5-8). Our hospital mortality rate had a close range between $4.78 \%$ and $10.8 \%$ similar to other series ${ }^{(9-13)}$.

Figure (4): Kaplan Meier long term survival curve. Survival at: 1 year - 94\%; 2 years - 90\%; 5 years $75.6 \%$; 10 years $-46.3 \%$.

\section{Survival Fur}

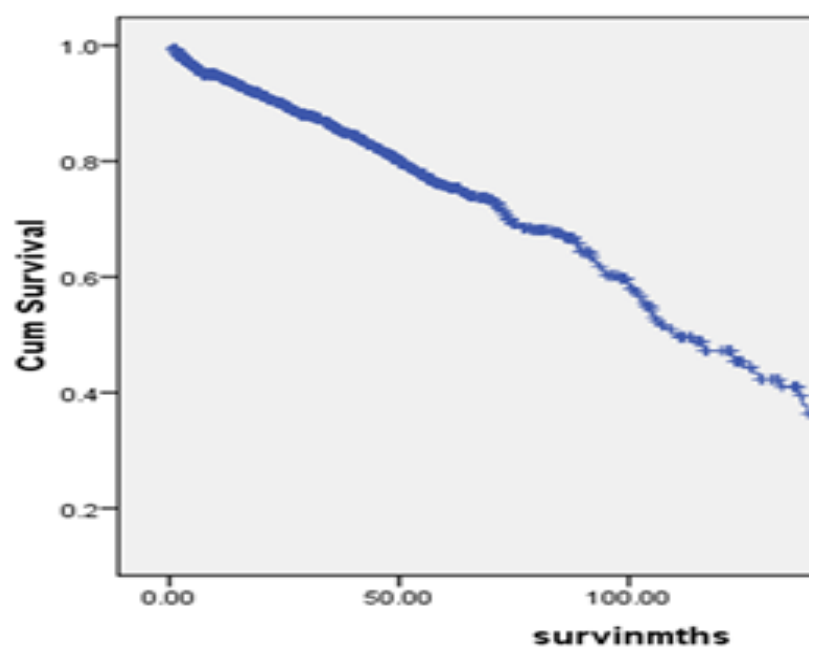


Figure (5): Survival comparison pre \& post 2009.

\section{Survival Functions}

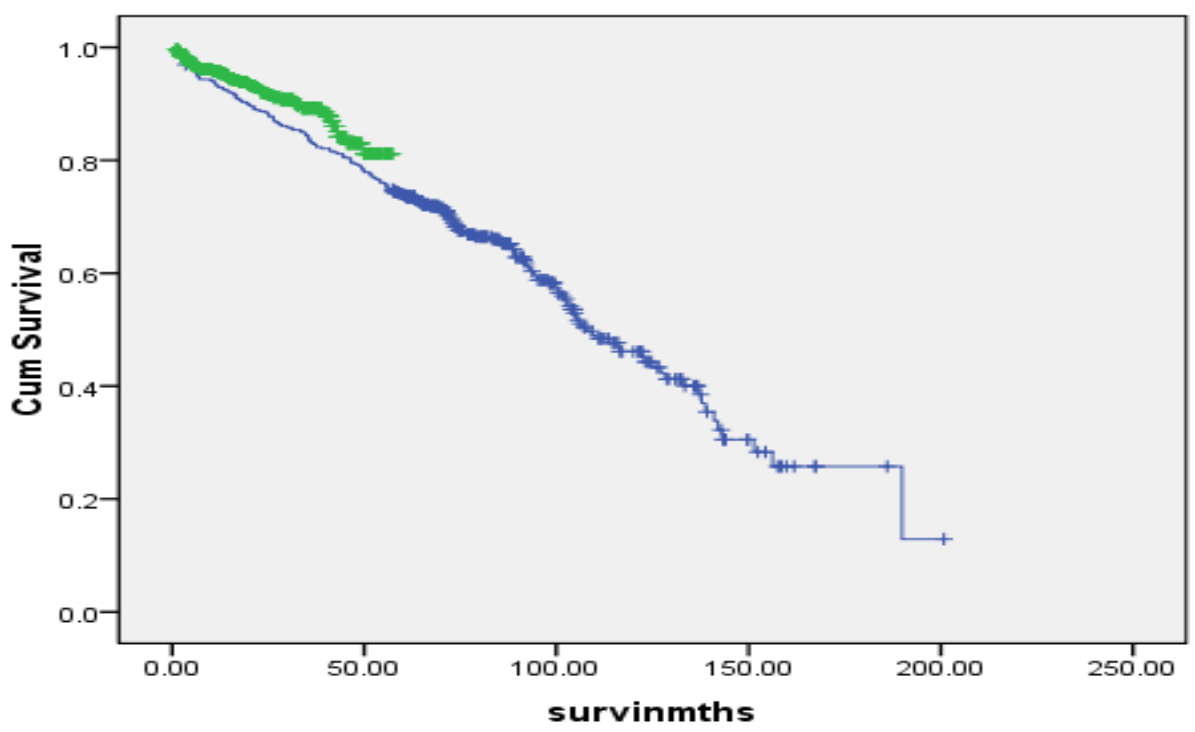

T 1 before Jan og

$\longrightarrow 2$ after Jan 09

Table (1): Descriptive and preoperative results

\begin{tabular}{|c|c|c|c|}
\hline characteristic & Group $1(n=472)$ & Group $2(n=607)$ & $\begin{array}{l}\text { significance of } \\
\text { difference }\end{array}$ \\
\hline mean age (yrs.) & $82.23 \pm 2.33$ & $82.89 \pm 2.66$ & $p<0.01$ \\
\hline females & $223(47.2 \%)$ & $235(38.7 \%)$ & $p=0.005$ \\
\hline diabetes & $69(14.6 \%)$ & $89(14.7 \%)$ & $p=0.98$ \\
\hline renal dysfunction & $10(2.1 \%)$ & $11(1.8 \%)$ & $p=0.40$ \\
\hline Hypertension & 272 ( $57.6 \%)$ & $428(70.5 \%)$ & $p<0.01$ \\
\hline Pulmonary problems & $38(8 \%)$ & $94(15.5 \%)$ & $p<0.01$ \\
\hline redo surgery & $7(1.5 \%)$ & $16(2.6 \%)$ & $p=0.19$ \\
\hline poor LV & $21(4.4 \%)$ & $34(5.6 \%)$ & $p=0.362$ \\
\hline Aortic surgery & $18(1.7 \%)$ & $13(1.2 \%)$ & $p=0.1$ \\
\hline
\end{tabular}

Table (2): Patient's risk, different surgical procedures and surgical priorities.

\begin{tabular}{|c|c|c|c|}
\hline characteristic & Group 1(n=472) & Group $2(n=607)$ & $\begin{array}{l}\text { significance of } \\
\text { difference }\end{array}$ \\
\hline $\begin{array}{l}\text { procedure } \\
\text { - isolated CABG } \\
\text { - isolated Valves } \\
\text { - CABG+valves }\end{array}$ & $\begin{array}{l}200(42.4 \%) \\
112(23.7 \%) \\
145(30.7 \%)\end{array}$ & $\begin{array}{l}229(37.7 \%) \\
185(30.5 \%) \\
177(29.2 \%)\end{array}$ & $p=0.09$ \\
\hline $\begin{array}{l}\text { priority } \\
\text { - elective } \\
\text { - urgent } \\
\text { - emergency }\end{array}$ & $\begin{array}{l}331(70.1 \%) \\
124(26.3 \%) \\
17(3.6 \%)\end{array}$ & $\begin{array}{l}420(69.2 \%) \\
175(28.8 \%) \\
11(1.8 \%)\end{array}$ & $p=0.19$ \\
\hline Mean add EuroSCORE I & $6.78 \pm 4.7$ & $8.59 \pm 3.04$ & $p<0.01$ \\
\hline Mean log EuroSCORE I & $12.11 \pm 10.1$ & $13.44 \pm 10.66$ & $p=0.04$ \\
\hline
\end{tabular}


Table (3): Postoperative outcome. Pulmonary, G.I. complications and S.Cr > 200 not requiring haemofiltration not different

* Average postop stay for 60 year old for $2009-2013=8.35$ d

\begin{tabular}{|l|l|l|l|}
\hline characteristic & Group 1 $(\mathrm{n}=472)$ & Group 2 $(\mathrm{n}=607)$ & significance of difference \\
\hline $\begin{array}{l}\text { C.V. event } \\
\text { - permanent }\end{array}$ & $10(2.1 \%)$ & $10(1.6 \%)$ & $\mathrm{p}=0.63$ \\
\hline haemofiltration & $9(1.9 \%)$ & $19(3.1 \%)$ & $\mathrm{p}=0.19$ \\
\hline reop for bleeding & $22(4.7 \%)$ & $33(5.4 \%)$ & $\mathrm{p}=0.28$ \\
\hline ICU stay & $31(6.6 \%)$ & $2.23 \mathrm{~d}$ & $\mathrm{p}=0.58$ \\
\hline Postop stay (mean) & $2.54 \mathrm{~d}$ & $13.7 \mathrm{~d} *$ & $\mathrm{p}=0.45$ \\
\hline hospital deaths & $14.42 \mathrm{~d}$ & $29(4.78 \%)$ & $\mathrm{p}<0.01$ \\
\hline
\end{tabular}

In contrast to other studies which showed a greater variability in mortality ranges with different exclusion criteria (14-21), mortality rate was as low as $1.7 \%$ following isolated mitral valve surgery for degenerative disease (23) and as high as $19.6 \%$ for combined mitral and CABG surgery (18). Risk stratification in this age group is highly desirable, the Euroscore was found to overestimate the operative risk in octagenarians by Stoica and colleagues. Although the Euroscore II was previously validated in our general population group (24) for first time CABG and keeping in line with the findings of Stoica and colleagues the Euroscore would have overestimated the mortality in our Octagenarians by $72 \%$. This may have resulted in a shift towards a more conservative management in this age group despite the fact that they could benefit more from surgical treatment with an acceptable outcome. In a study by El-Mistekawy et al., he found that the society of the thoracic surgery risk scoring (STS scoring system) was found to have a closer estimate of the mortality rates in octagenarians undergoing cardiac surgery (25). Between Jan.2009-June.2013 our 30 day hospital mortality had significantly dropped by $6.02 \%$. This drop may reflect the advancement in all aspects of adult cardiac surgery, meticulous surgery and high level of care in the postoperative ITU. A greater percentage of group 2 were discharged home $75 \%$ but their functional status was not assessed upon their discharge to their homes, but judging from the paper by Aw et al., (26) who found that the major factor affecting the patients' independency post operatively is their preoperative state, one could predict that if they were independent preoperatively they should still remain to do so with or without mild impairments. Our long term survival curve (fig. 4) showed that the survival at: $1,2,5,10$ years was $94 \%, 90 \%, 75.6 \%$ and $46.3 \%$ respectively. The comparative survival curve (Fig 5) between the 2 groups shows a better early survival rates with a predicted better long term outcome. Further studies are required to stratify the parameters which determine the areas of care that may produce a better outcome in this age group.

\section{Conclusion:}

Our results show an increasing workload of elderly patients with higher risk scores. Octagenarians are having an improvement in their hospital mortality with an acceptable complication rate and a proposed better long term survival, hence encouraging surgeons to take on more of these patients rather than a more conservative approach.

\section{Conflicts of Interest}

None of the authors have any competing interests to declare.

\section{Authors' Contributions}

FM: Wrote the article, collected data \& is the corresponding author.

VS: Statistical analysis

MK: Data Collection

AD: Supervising consultant and did the critical reading. 


\section{Refrences:}

1. Fruitman DS, MacDougall CE, Ross DB: Cardiac surgery in octogenarians: can elderly patients benefit? Quality of life after cardiac surgery. Ann Thorac Surg 1999; 68: 2129-2135.

2. Zingone B, Gatti G, Rauber E, Tiziani P, Dreas L, Pappalardo A, Benussi B, Spina A: Early and late outcomes of cardiac surgery in octogenarians. Ann Thorac Surg 2009; 87: 71-78.

3. Akins CW, Daggett WM, Vlahakes GJ, Hilgenberg AD, Torchiana DF, Madsen JC, Buckley MJ: Cardiac operations in patients 80 years old and older. Ann Thorac Surg 1997; 64: 606-614, discussion 614-615.

4. Williams DB, Carrillo RG, Traad EA, Wyatt $\mathrm{CH}$, Grahowksi R, Wittels $\mathrm{SH}$, Ebra G: Determinants of operative mortality in octogenarians undergoing coronary bypass. Ann Thorac Surg 1995; 60: 10381043.

5. lung B, Cachier A, Baron G, et al. Decision-making in elderly patients with severe aortic stenosis: why are so many denied surgery? Eur Heart J 2005;26:2714 -20.

6. Varadarajan P, Kapoor N, Bansal RC, Pai RG. Clinical profile and natural history of 453 nonsurgically managed patients with severe aortic stenosis. Ann Thorac Surg 2006;82:2111-5.

7. Mirabel $M$, lung $B$, Baron $G$, et al. What are the characteristic of patients with severe, symptomatic, mitral regurgitation who are denied surgery? Eur Heart J 2007;28:1358-65.

8. Alexander KP, Roe MT, Chen AY, et al. Evolution in cardiovascular care for elderly patients with non-ST-segment elevation acute coronary syndromes: results from the CRUSADE National Quality Improvement Initiative. J Am Coll Cardiol 2005;46:1479-87.

9. Akins CW, Daggett WM, Vlahakes GJ, et al. Cardiac operations in patients 80 years old and older. Ann Thorac Surg 1997;64:606 -14.

10. Stoica SC, Cafferty F, Kitcat J, et al. Octogenarians undergoing cardiac surgery outlive their peers: a case for early referral. Heart 2006;92;503-6.

11. Rady MY, Ryan T, Starr NJ. Perioperative determinants of morbidity and mortality in elderly patients undergoing cardiac surgery. Crit Care Med 1998;26:225-35.

12. Scandroglio, A.M., Finco, G., Pieri, M., Ascari, R., Calabrò, M.G., Taddeo, D., Isella, F., Franco, A., Musu, M., Landoni, G. and Alfieri, O., 2015. Cardiac surgery in 260 octogenarians: a case series. BMC anesthesiology,15(1), p.1

13. Usama $\mathrm{AH}$, Hanan IR, Mohamed FI. Operative Results of Coronary Artery Bypass Surgery in Elderly Patients: Local Experience. J Egypt Soc Cardiothorac Surg 2011; 19 (3-4): 38-43.

14. Collins SM, Brorsson B, Svenmarker S, Kling PA, Aberg T. Mediumterm survival and quality of life of Swedish octogenarians after open-heart surgery. Eur J Cardiothorac Surg 2002;22:794-801.

15. Huber $\mathrm{CH}$, Goeber V, Berdat P, Carrel T, Eckstein F. Benefits of cardiac surgery in octogenarians. A postoperative quality of life assessment. Eur J Cardiothorac Surg 2007;31:1099 -105.

16. Kolh P, Kerzmann A, Honore C, Comte L, Limet R. Aortic valve surgery in octogenarians: predictive factors for operative and longterm results. Eur J Cardiothorac Surg 2007;31: 600-6.

17. Rady MY, Johnson DJ. Cardiac surgery for octogenarians: is it an informed decision? Am Heart J 2004;147:347-53.

18. Alexander KP, Anstrom KJ, Muhlbaier LH, et al. Outcomes of cardiac surgery in patients age 180 years: results from the National Cardiovascular Network. J Am Coll Cardiol 2000; 35:731- 8.

19. Melby SJ, Zierer A, Kaiser SP, et al. Aortic valve replacement in octogenarians: risk factors for early and late mortality. Ann Thorac Surg 2007;83:1651-7.

20. de Vincentiis $C$, Kunkl AB, Trimarchi $S$, et al. Aortic valve replacement in octogenarians: is biologic valve the unique solution? Ann Thorac Surg 2008;85:1296 -301.

21. Nagendran J, Norris C, Maitland A, Koshal A, Ross DB. Is mitral valve surgery safe in octogenarians? Eur J Cardiothorac Surg 2005;28:83-7.

22. Johnson WM, Smith JM, Woods SE, Hendy MP, Hiratzka LF. Cardiac surgery in octogenarians. Does age alone influence outcomes? Arch Surg. 2005;140:1089 -93.

23. DiGregorio V, Zehr KJ, Orszulak TA, et al. Results of mitral surgery in octogenarians with isolated nonrheumatic mitral regurgitation.
Ann Thorac Surg 2004;78:807-14.

24. Khan A, Srivastava V, Mourad F, Richards R, Bose A: Evaluation of EuroSCORE II for elective isolated first time CABG patients. Journal of Cardiothoracic Surgery 2013 8(Suppl 1): P72.

25. El-Mistekawy E, Tran D, Mcdonald B, Ruel M, Mesana TG, Lam BK. The Value of Risk Algorithms in Predicting Outcomes for Octogenarians Undergoing Aortic Valve Replacement With or Without CABG. J Egypt Soc Cardiothorac Surg 2012; 20 (1-2): 135 40 .

26. Wu AW, Yasui Y, Alzola $C$, et al. Predicting functional status outcomes in hospitalized patients aged 80 years and older. J Am Geriatr Soc 2000;48:S6-15. 